\title{
How American-based Television Commercials Portray Convicts, Correctional Officials, Carceral Institutions, and the Prison Experience
}

\author{
Jeffrey lan Ross \& Vickie Sneed
}

To cite this article: Jeffrey lan Ross \& Vickie Sneed (2018) How American-based Television Commercials Portray Convicts, Correctional Officials, Carceral Institutions, and the Prison Experience, Corrections, 3:2, 73-91, DOI: 10.1080/23774657.2017.1318318

To link to this article: https://doi.org/10.1080/23774657.2017.1318318

曲 Published online: 10 May 2017.

Submit your article to this journal \lceil

Џll Article views: 42

Q View related articles $\longleftarrow$

View Crossmark data ¿ 


\title{
How American-based Television Commercials Portray Convicts, Correctional Officials, Carceral Institutions, and the Prison Experience
}

\author{
Jeffrey lan Ross ${ }^{a, b}$ and Vickie Sneed ${ }^{a}$ \\ aSchool of Criminal Justice, University of Baltimore, Baltimore, Maryland, USA; ${ }^{b}$ Criminology, Criminal Policy \\ and Police Science, Ruhr University, Bochum, Germany
}

\begin{abstract}
The manner in which deviant and marginalized groups are portrayed in popular culture shapes public perceptions and policy responses. These messages are communicated through a variety of channels. Over the past decade, scholarly interest in the portrayal of prisoners, correctional officers, and correctional institutions has increased. One of the unexplored, important, and relatively contemporary mediums through which inmates, correctional officers, and carceral spaces have been portrayed is through commercials. These messages appear via print, television, and the Internet. In an attempt to understand the content and context of these commercials, the following article presents the results of a content analysis of American-based television commercials that feature convicts, correction officials, prison settings, and/or the carceral experience.
\end{abstract}

\section{KEYWORDS}

Television; commercials; convicts; correctional officials; carceral institutions; prison experience

\section{Introduction}

A correctional officer escorts a prisoner, wearing an orange jump suit, to a visiting cell where a man, who appears to be his lawyer, is talking on a cell phone. The man on the phone states, "Well that's great news. I appreciate it. Good bye." The convict looks up in a hopeful manner. Fully expecting to hear positive news regarding his incarceration, the lawyer then says to the inmate, "I've got some fantastic news." The prisoner states "I'm outta here?" The attorney responds, "No Geico, I just saved myself a bunch of money on my car insurance."

This television commercial and other similar ones are aired on commercial television stations on a periodic basis. Correctional facilities and the people who live and work there are occasionally used in advertising campaigns for shock and/or entertainment value. By grabbing the public's attention, these commercials can enable corporations and organizations (e.g., political and advocacy) to sell products and services, and/or promote and gather support for certain points of view. Many print and television ad campaigns feature prisoners, ${ }^{1}$ correctional officers, jails, prisons, and practices that occur in these facilities. Less understood are how these unique institutions and individuals are characterized, the situations in which prisoners and correctional workers are used, and the subtle messages that are communicated. 
Just like newspapers, television programs, movies, and educational institutions, over time many of these mechanisms become part of the cultural industries that have developed in a city, state, or country (Schiller, 1989). The popular culture of prisons (Ross, 2003; Wright, 2000) includes, but is not limited to, commercial films (e.g., Cool Hand Luke, etc.), television serial drama (e.g., Prison Break, etc.), quasi-documentary television series (e.g., Locked Up, etc.), and prison museums (e.g., Wilson, 2008). Although many of these cultural mechanisms, as they relate to the field of corrections, have been reviewed and analyzed, this article examines how American-based television commercials feature correctional settings in general, and prisoners and correctional officials in particular.

Why is this important? The popular culture of corrections, including advertisements that feature convicts, correctional officers, and administrators, contributes to the normalization of the carceral state, which promotes unrealistic perceptions of jails, prisons, and the people who live and work there, and frustrates efforts to reform jails and prisons (Rosenberger \& Callanan, 2011).

Before continuing, it is important to answer a handful of questions. To begin with, what does normalization mean in this context? Essentially normalization relates to a widespread acceptance of a practice or, at the very least, a failure to be bothered or affected by it. Additionally, what is the carceral state? The carceral state acknowledges that through a combination of policies, practices, laws, and institutions, most advanced industrialized democracies have become increasingly punitive (e.g., Pratt, Brown, Brown, Hallsworth, \& Morrison, 2013). Moreover, to support and maintain what some also refer to as a law-andorder approach, there has been a widespread and complimentary acceptance among the public that jails, prisons, and other similar correctional facilities are the best way to deal with lawbreakers and deviants. The collective effect is that a phenomenal amount of resources (in particular taxpayer money) is channeled into supporting this infrastructure, resulting in a waste of human life and potential (Gottschalk, 2014; Murakawa, 2014; Weaver \& Lerman, 2010).

Building upon this original notion is the concept of the "shadow" carceral state or "shadow" penal state. These terms, crafted by Beckett and Murakawa (2012), refer to "government policies, legal doctrine, and institutions with the power to impose sanctions that either mimic the coercive practices widely considered to be of punishment ... or impose significant hardship and carry with them social and political opprobrium" (p. 239). Building upon the state crime literature (e.g., Barak, 1991; Ross, 1995/2000, 2000b; Rothe, 2009), it is easy to understand this explanation of the negative features of contemporary governments and the administration.

Similar to the concept of the carceral state is the notion of mass or hyperincarceration (Simon, 2000, 2010). This phenomenon concerns the exponential increase in the number of individuals that American local, state, and federal criminal justice systems have incarcerated over the past two decades (Gottschalk, 2010, 2011). Alternative explanations for this phenomenon are provided by Garland (2001) who sees the growth as an embodiment of Americans' need to control lawbreakers, and Wacquant (2001) who interprets the increase in jails, prisons, and prisoners as a state response to dealing with a dislocated and largely unemployed and unemployable urban (typically African American) underclass.

To support the carceral state, including the construction, operation, and staffing of correctional facilities, an insidious narrative has been developed, disseminated, sustained, and widely accepted. In general, a simplistic story or narrative is told to the public, one 
that can be easily grasped, but it is often a distortion of the truth about who criminals and victims are, what law breaking is, and the role, purpose, and accomplishments of jails and prisons. This communication is disproportionately full of myths, misconceptions, misrepresentations, and misinformation (Ross, 2012). ${ }^{2}$ This process has been accomplished through a variety of actors and communication channels. Although Althusser (1971) championed the notion that government agencies are responsible for this kind of activity, Gramsci (1971/2011) pointed out how the existing culture and news media could also be a conduit for these actions. The dissemination of messages about the carceral state can also assisted by the public's lack of knowledge, their alienation, apathy, and tendency to obey authority (Ross, 2000a, chapter 5). The messages that support the existence of the carceral state are embedded in the ideologically tinged popular discourse on the role and meaning of jails, prisons, prisoners, and correctional officers. Attitudes and perceptions regarding jails, prisons, inmates, and correctional workers may be shaped through the process identified in cultivation theory (e.g., Gerbner, 1998). Overall this communication and rhetoric minimizes our ability to properly reform corrections and to deal with individuals who are considered deviants and criminals.

What are some of the core messages of the carceral state? Most of those communications are aimed at supporting the institutional goals of jails and prisons (i.e., to punish, deter, and rehabilitate inmates, and keep the community safer). Most of the scholarly research suggests that correctional facilities generally do a good job of punishing those convicted of a crime, however their ability to achieve the other goals is more difficult (e.g., Cullen \& Gendreau, 1989).

As part of the trend of increasing correctional populations in many countries, the demand for carceral facilities has grown, too. There are only so many temporary housing solutions (e.g., double and triple bunking, repurposing of gyms and cafeterias as cell space, etc.) that can be used before a proposal is introduced to build a new correctional facility.

Supporting this vast infrastructure is an enormous array of individuals and institutions that influence the public, correctional workers, and politicians pushing for continued growth of our jails and prisons. One of the more important elements in this mix is the advertising industry. How they manage to exert their influence is less understood. Thus, an exploratory analysis of how commercials portray corrections is warranted. ${ }^{3}$

A study on the amount, variability, and meanings of commercials featuring prisoners, correctional officers, wardens, and correctional facilities lies at the crossroads of a number of interrelated scholarly fields, including cultural criminology, visual criminology, and corrections. Cultural criminology sees the primacy of culture as a context in which to understand crime, criminals, and responses to it. In addition to a focus on ethnographic methods, this field examines how numerous cultural industries portray deviant subcultures (Ferrell, Hayward, \& Young, 2008). Visual criminology deals more with how images are constructed, used, and framed (Hayward, 2009; Hayward \& Presdee, 2010). Both subdisciplines are interested in the role of cultural products, particularly in their power to shape and reinforce dominant stereotypes of marginalized sectors of society, and their meaning. The third area of research is the field of corrections, which examines not only inmates, but also correctional officers, correctional workers, and prison administrators. This discipline also investigates the policies 
and practices that these unique organizations engage in, and the effects of jails, prisons, and other correctional facilities.

\section{Studies that analyze commercials}

\section{Introduction}

Commercials come in all shapes and sizes. In modern-day America, these include print (i.e., newspapers, magazines, flyers, etc.), billboards, websites, social media, and television. According to Williamson (1994):

Advertisements are one of the most important cultural factors molding and reflecting our life today. They are ubiquitous, and an inevitable part of everyone's lives: even if you do not read a newspaper or watch television, the images posted over our urban surroundings are inescapable. Pervading all the media, but limited to none. (p. 11)

To begin with, almost all households in the United States have a television (Comstock, 1991; Kellner, 1990; Signorielli, 1991). On average, a U.S. household has a television on for close to 7 hours a day (Signorielli \& Lears, 1992), and adults watch more than 30 hours of television each week (Bretl \& Cantor, 1988). Although this information is dated, and television-viewing habits have most definitely changed, a 2014 study conducted by the U. S. Bureau of Labor Statistics (2015) indicates that adults watch a daily average of 2.82 hours, with a weekly total of 19.74 hours. According to more recent statistics, $99 \%$ of all U.S. households own at least one television set, with household members watching a little over 5 hours of television programming a day (Anonymous, 2016). Even though the bulk of this research is derived from self-reports, this amount of screen time comprises a considerable amount of a person's daily activities.

With the invention of television came a need to pay for the programming. In general, the amount of time that is turned over to commercials and promotional activities has been slowly increasing (Elliott, 1995). During the late 1980s, approximately 1 out of every 5 hours of television programming consists of commercials, and it is estimated that the average American watches 30,000 commercials in a given year and two million over their lifetime (Bretl \& Cantor, 1988; Comstock, 1991). By the mid-1990s reports suggested that the amount of time devoted to commercials increased from 15 to 16 minutes per hour (Walstead, 1997).

Approximately $85 \%$ of daily adult viewers are exposed to nearly 73 minutes of television commercials, leading to over $\$ 71$ billion in television advertising revenue in 2015 (Anonymous, n.d., 2010). Although adult viewers average 26 advertising breaks daily, or approximately 9,500 television commercials in a year, children see nearly double that amount during a one-year period, watching at least 16,000 commercials a year (Anonymous, n.d., 2010). The amount spent on commercials has also increased. In the late 1990s, television commercials cost advertisers about $\$ 32$ billion a year (Tribune News Service, 1998, p. 6).

\section{Methods used to analyze commercials}

Prior research has shown that researchers appear to use the same methods when obtaining sample sizes, as well as coding the commercials (Ball, Liang, \& Lee, 2009; Mastro \& Stern, 2003). A study of African American representation in direct-to- 
consumer (DTC) pharmaceutical commercials collected more than 1,600 television commercials over a 2 -week period, during primetime, daytime, and national news programming (Ball et al., 2009). Out of the total amount collected, a little over 125 were identified as DTC pharmaceutical commercials, thereby determining the sample (Ball et al., 2009). From there, the sample was assessed by the characteristics of the advertisement (i.e., brand name, frequency with which the commercial aired, etc.), along with coding for the leading roles of each commercial's storyline, and the race of those in those roles (Ball et al., 2009). Two trained coders were used to code each commercial in the sample, and using Perreault and Leigh's (1989) formula for intercoder reliability, the coders produced a result of 0.96 .

\section{Content analyses of commercials}

One of the most dominant ways to analyze commercials is through content analysis (Riff, Lacy, \& Fico, 2014). Research on analyzing the content of television commercials tends to focus on a select number of subjects. The majority of this kind of analysis typically clusters around gender roles and stereotypes (e.g., Allan \& Coltrane, 1996; Bardwick \& Schumann, 1967; Bretl \& Cantor, 1988; Courtney \& Whipple, 1985; Dominick \& Rauch, 1972; Ferrante, Haynes, \& Kingsley, 1988; Geis, Brown, Jennings, \& Porter, 1984; Gilly, 1988; Graig, 1992; Hall \& Crum, 1994; Knill, Pesch, Pursey, Gilpin, \& Perloff, 1981).

Other content analyses of commercials have examined how race is depicted. An example of content analyses in commercials can be found in Mastro and Stern's (2003) study on the representation of race in television commercials. Researchers looked at three weeks of primetime programming on all major television networks, and with four trained coders, they produced a sample size yielding a little over 2,800 commercials (Mastro \& Stern, 2003). To obtain the one-week sample, only national commercials were coded; local commercials and commercials promoting sporting events, movies, or television shows were omitted from the analysis (Mastro \& Stern, 2003). Additionally, coders only analyzed the first three actors who spoke in each commercial (Mastro \& Stern, 2003).

Finally, some scholarly research has examined the frequency of violence and aggression in television commercials. Maguire, Sandage, and Weatherby (2000), review the content of 1,699 commercials and conclude that few if any commercials have this kind of content. Scharrer, Bergstrom, Paradise, and Ren (2006) retrieved a weeks' worth of television programs. The sample had 4,347 commercials and from this number identified 536 that displayed violence and/or aggression. These were further analyzed. The researchers concluded that violence and aggression were often paired with humor to blunt the impact of the advertisement. Hetsroni (2010, 2011) compares a sample of television commercials in the United States with one in Israel and concludes that about $2.5 \%$ of the U.S. ones and $1.5 \%$ of the Israel advertisements contain violent content. This was followed up with a public opinion survey that indicates that the public overestimates the amount of violence in commercials. Alternative research looking at the prevalence of violence in commercials has examined this content during sports casts (e.g., Tamburro, Gordon, D’Apolito, \& Howard, 2004).

The researchers found that by only coding the first three actors who spoke, they would eliminate any questions about the role the actor played (Mastro \& Stern, 2003). From there, each commercial was coded by product type, the relationship the character or characters had to the product, the behavior of those in the commercial 
- that is, were the characters at work or at play-as well as the family status of the character(s), the attractiveness of the character(s), age of the character(s), and so on (Mastro \& Stern, 2003).

Researchers determined that White males were the most predominately featured speakers in commercials, whereas the majority of African American characters were represented in food and financial services commercials (Mastro \& Stern, 2003). Unlike Whites and African Americans, Latino and Asian characters were not seen using the product being advertised in the commercial, whereas Native Americans were rarely seen in any of the commercials and therefore excluded from further analysis (Mastro \& Stern, 2003).

Additionally, Baumann and Ho (2014) conducted a qualitative analysis of cultural schemas for racial representation present in Canadian television commercials. To construct a diverse sample, the researchers recorded commercials featured on three Canadian television networks over 21 evenings during an 18-month period (Baumann \& Ho, 2014). To limit their sample size, Baumann and Ho only coded commercials that featured characters in situations related to food and dining. Their final sample featured nearly 230 commercials with more than 1,060 characters.

Choosing to examine three races-White, African American, and East/Southeastern Asian-Baumann and Ho (2014) compared the percentage of races featured in a commercial against the type of commercial (i.e., featuring fast food, whole foods, etc.), determining that Whites were over-represented in commercials focusing on whole foods and processed foods (Baumann \& Ho, 2014). However, African Americans and East/ Southeastern Asians were over-represented in all other food commercials, with both races being featured the most in fast food commercials (Baumann \& Ho, 2014). Additionally, Baumann and Ho observed that each race featured its own cultural schema, with four schemas for Whites, and only one each for African-Americans and East/Southeastern Asians.

\section{Analysis of commercials with criminal justice themes}

Despite the pervasiveness of crime, criminals, and criminal justice in American society, a body of literature concerning the depiction of these themes in commercials has not yet been created. When scholars examine these issues, it is usually done in a parenthetical fashion. For example, the 1988 Bush/Dukakis presidential race is infamous for Republicans using the highly controversial crime committed by Willie Horton while out on parole in their negative advertising against Dukakis (Anderson, 1995). ${ }^{4}$ But this commercial appears to be a random case among all commercials featuring correctionsrelated themes used for analysis. Thus, a study examining the portrayal of prisoners, correctional officials, and carceral settings should contribute to this unexamined knowledge base.

In short, the researchers decided to analyze the commercials featuring prisoners, correctional officials, and so on using the basic principles of content analysis (e.g., Holsti, 1969; Krippendorf, 1981). This is a grounded research study with the objective of understanding the basics of this body of work. 


\section{Method}

To begin with, a document prepared by the principal investigator, with a list of relevant commercials and URLs to each commercial, which predated this data collection effort, was reviewed. Next, a search was conducted to confirm that the URLs were still active. Those that were not active were then placed on a list to conduct a further search for the commercials.

From there, to retrieve commercials featuring prisons, convicts, and correctional officers, numerous searches of the Google search engine and the popular website YouTube were made. Search terms included chain gangs, convict(s), correctional officers, inmates, jails, offenders, officers, prison, prison officials, prisoner(s), and warden(s). The URLs of relevant commercial clips were copied and subjected to content analysis. Videos were limited to products and services that were marketed in the English language and sold in the United States. If a product was sold in the United States, such as Renault cars, and the commercial was in English but was oriented toward the United Kingdom market, then it was not included in the database. This step resulted in an initial sample size of 34 commercials. ${ }^{5}$ Our goal was not to derive conclusions based on a sample of the available universe, but on the total available population, which is manageable. We believe that appropriate and cautious inferences can be made with this time period.

A basic coding sheet was constructed. Keeping in mind that the development of a coding instrument is an iterative process, during the process of data collection and coding, the coding sheet had to be revised several times to capture the information contained in the commercials. ${ }^{6}$ The search for appropriate URLs was conducted between September 1, 2015 and December 1, 2015 with initial coding concluding on February 25, 2016. The commercials were initially coded on a total of 11 variables that the researchers deemed to be important in understanding the breadth and depth of the content. A follow-up coding of the commercials focusing on more substantive/latent issues was conducted between September 1, 2016 and October 20, 2016. These dates are included here as content on the World Wide Web, especially YouTube, is ever changing and not always available. ${ }^{7}$

In addition to the coauthor, the commercials were viewed and coded by two other research assistants. Using the coding sheet developed for this study, the coauthor viewed the original sample a minimum of two times to code each commercial. Some of the commercials in the original sample required additional viewing due to the number of prisoners, prison officials, and/or activities taking place in the commercial. Once this was completed, the information was entered into a SPSS (Version 23) database for future use. ${ }^{8}$

Additional coding was conducted to better understand the latent content of the commercials. This resulted in the coding of five new variables to test the type of humor characterized in the each commercial, the political correctness (or incorrectness) of the commercials, and how each actor (e.g., prisoner, prison official) was viewed. ${ }^{9}$

\section{Results}

\section{Introduction}

After an exhaustive search, a total of 33 commercials that had been archived on the web provided the initial sample for analysis. The researchers acknowledge that this is a sample of convenience and that, in all likelihood, more commercials were aired during the time 
period (1960-2015), but these are the ones that were available through the web at the time of this study. The information reviewed below reflects a logical ordering of the content in the commercials.

\section{Year commercials aired}

Between 1970 and 2015, at total of 33 commercials that included correctional facilities, prisoner(s), and/or correctional officers and administrators were identified (Table 1). The sample is not continuous by years. Prior to 2007, the sample set saw one commercial per year featuring prisoners. Between 2007 and 2014, an average of 3.17 commercials per year featured correctional themes. $97 \%$ of commercials in the sample $(n=32)$ provided the year in which they aired on national television. Prior to 2007, of the 14 commercials viewed and coded, only eight featured correctional officials. Of those eight, seven were characterized as correctional officers, whereas only one commercial saw multiple representations of correctional officials, meaning a correctional officer(s) and warden were portrayed.

\section{Length of commercial}

Not all commercials viewed were of the same length (Table 2). The total length of each commercial, in seconds, was as follows: the majority viewed (11/33\%) was between 39 to 181 seconds. Only $6.1 \%(n=2)$ of the commercials were 29 seconds in length, and $30.3 \%$ $(n=10)$ of the commercials lasted only 30 seconds. We found that $21.2 \%(n=7)$ of the commercials viewed were 31 seconds in length, and $6.1 \%(n=2)$ of the commercials lasted 32 seconds. It must be noted that there is one outlier-one 25 -second commercial-which exists in the data set. The average length of all commercials is 45.18 seconds.

Table 1. Year commercials aired.

\begin{tabular}{lc}
\hline & $N(\%)$ \\
\hline 1970 & $1(3.0)$ \\
1976 & $1(3.0)$ \\
1978 & $1(3.0)$ \\
1986 & $1(3.0)$ \\
1988 & $1(3.0)$ \\
1990 & $1(3.0)$ \\
1998 & $1(3.0)$ \\
1999 & $1(3.0)$ \\
2000 & $1(3.0)$ \\
2001 & $1(3.0)$ \\
2002 & $1(3.0)$ \\
2004 & $1(3.0)$ \\
2005 & $1(3.0)$ \\
2006 & $1(3.0)$ \\
2007 & $3(9.1)$ \\
2008 & $1(3.0)$ \\
2011 & $2(6.1)$ \\
2012 & $4(12.1)$ \\
2013 & $4(12.1)$ \\
2014 & $3(9.1)$ \\
2015 & $1(3.0)$ \\
Missing & $1(3.0)$ \\
Total & $33(97.0)^{\mathrm{a}}$ \\
\hline Ond com
\end{tabular}

${ }^{\mathrm{a}}$ One commercial did not have a date to coincide with when it was aired. 
Table 2. Length of commercials.

\begin{tabular}{lc}
\hline Seconds & $N(\%)$ \\
\hline 25 & $1(3.0)$ \\
29 & $2(6.1)$ \\
30 & $10(30.3)$ \\
31 & $7(21.2)$ \\
32 & $2(6.1)$ \\
39 & $1(3.0)$ \\
42 & $1(3.0)$ \\
51 & $1(3.0)$ \\
55 & $1(3.0)$ \\
58 & $1(3.0)$ \\
60 & $1(3.0)$ \\
61 & $1(3.0)$ \\
63 & $1(3.0)$ \\
69 & $1(3.0)$ \\
71 & $1(3.0)$ \\
108 & $1(3.0)$ \\
181 & $1(3.0)$ \\
Total & $33(100)$ \\
\hline
\end{tabular}

Table 3. What is being advertised?

\begin{tabular}{lr}
\hline Seconds & \multicolumn{1}{c}{$N(\%)$} \\
\hline Product & $22(66.7)$ \\
Service & $7(21.2)$ \\
Cause/organization & $4(12.1)$ \\
Total & $33(100)$ \\
\hline
\end{tabular}

\section{What is being advertised?}

The commercials depicted a broad range of products and services (Table 3). Some were also public service type announcements (PSAs). In general, television commercials released to the American market that feature convicts, correctional officers, and correctional settings have focused on the selling of clothing items, foodstuffs, personal hygiene products, household cleaning products, and political campaigns. More specifically, 66.7\% $(n=22)$ advertised a product (e.g., Alka Seltzer, Heinz Ketchup, etc.). Services accounted for $21.2 \%(n=7)$ (i.e., a bail bonds company), whereas $12.1 \%(n=4)$ advertised a cause or organization, such as a child abuse public service announcement.

\section{Message(s) packaged around advertisement}

One of the most important components that were coded demonstrates the type of message found in each advertisement (Table 4). Close to one third $(27.3 \%, n=9)$ displayed escape attempts, whereas $6.1 \%(n=2)$ suggested the sexual assault of a prisoner. Of our sample, $6.1 \%$ $(n=2)$ indicated impending injury (nonsexual assault) to a prisoner, and $6.1 \%(n=2)$ displayed prisoners being visited. Of our sample 18.2\% $(n=6)$ had multiple messages packaged around the advertisement, whereas $36.2 \%(n=12)$ demonstrated a miscellaneous message that was not applicable to the selections given. 
Table 4. Message(s) packaged around advertisement.

\begin{tabular}{lc}
\hline & $N(\%)$ \\
\hline Escape attempts & $9(27.3)$ \\
Suggested sexual assault & $2(6.1)$ \\
Impending injury (nonsexual assault) to a prisoner & $2(6.1)$ \\
Visiting & $2(6.1)$ \\
Multiple messages & $6(18.2)$ \\
Miscellaneous & $12(36.4)$ \\
Total & $33(100)$ \\
\hline
\end{tabular}

\section{Number of prisoners depicted}

To get a sense of how prominently prisoners were depicted in the commercials, their numbers were coded (Table 5). Only 9.1\% $(n=3)$ did not include prisoner(s) in the commercial, though it was alluded that a prisoner(s) did exist. However, $63.6 \%(n=21)$ of the commercials had one to five prisoners, and $15.2 \%(n=5)$ represented six to 10 prisoners. Additionally, $6.1 \%(n=2)$ of the commercials viewed found 11 to 15 prisoners represented, and $6.1 \%(n=2)$ had $21+$ prisoners a commercial. Because the number of prisoners appearing in the commercials was not coded individually, we cannot, without recoding, determine an average number of prisoners for our sample. However, based on the number of prisoners in each group, we can determine that the majority of commercials in our sample had one to five prisoners in them.

\section{Gender of prisoner(s)}

Prisoners of both genders were depicted in the commercials analyzed (Table 6). The majority of inmates, $69.7 \%(n=23)$, were males, whereas $9.1 \%(n=3)$ of prisoners were female. Three commercials featured male and female prisoners, 9.1\% $(n=3)$, and $12.1 \%(n$ $=4$ ) did not feature prisoners. Those that did not depict prisoners implied that prisoners did exist via the presence of prison officials. Three commercials featured automobiles instead of humans to represent prisoners. In addition, one commercial was designed in such a way that prisoners could be heard behind the prison walls but could not be seen. Because the voices in this commercial were male, and the cars in the previously mentioned

Table 5. Number of prisoners depicted.

\begin{tabular}{lc}
\hline & $N(\%)$ \\
\hline 0 & $3(9.1)$ \\
$1-5$ & $21(63.6)$ \\
$6-10$ & $5(15.2)$ \\
$11-15$ & $2(6.1)$ \\
$21+$ & $2(6.1)$ \\
Total & $33(100)$ \\
\hline
\end{tabular}

Table 6. Gender of prisoner(s).

\begin{tabular}{lc}
\hline & $N(\%)$ \\
\hline Males & $23(69.7)$ \\
Females & $3(9.1)$ \\
Multiple representation & $3(9.1)$ \\
No representation & $4(12.1)$ \\
Total & $33(100)$ \\
\hline
\end{tabular}


commercials were driven hyperaggressively (a stereotype associated with males), the gender coding for these four commercials was designated as male.

\section{Race/ethnicity of prisoner(s)}

Another detail worth considering is the race/ethnicity of the inmates (Table 7). The majority of prisoners featured in commercials were White $(48.5 \%, n=16)$, whereas $9.1 \%(n=3)$ featured an African American prisoner. Alternatively 33.3\% $(n=11)$ featured multiple races, and $9.1 \%(n=3)$ did not feature prisoners at all. Those commercials that did not feature prisoners implied that prisoners did exist via the presence of prison officials.

\section{Number of prison official(s) depicted}

For this variable, we looked at the number of prison officials (e.g., correctional officers, wardens, and administrators) depicted in each commercial (Table 8). The majority of commercials featured either no prison official $(16 / 48.5 \%)$ or one to five prison officials $(16 / 48.5 \%)$, whereas one commercial $(n=3)$ had 11 to 15 prison officials. As with the average number of prisoners, coding for the average number of prison officials was done in groups. Because of this, we found that nearly $50 \%$ of the commercials sampled featured one to five prison official(s), whereas nearly $50 \%$ did not.

\section{Type of prison official(s) depicted}

Less than one half of the commercials (16/48.5\%) portrayed prison officials (Table 9). Of the commercials that included a prison official, $82.35 \%$ of the individuals were correctional officers. It is curious to note that all commercials that featured a warden also featured a correctional officer, however there was not a single commercial that featured just a warden.

\section{Gender of prison official(s)}

Again, males dominated the representation of prison officials. Men were depicted $54.5 \%$ $(n=18)$ of the time in the sample, whereas a woman $(3 \%)$ portrayed a correctional

Table 7. Race/ethnicity of prisoner(s).

\begin{tabular}{lc}
\hline & $N(\%)$ \\
\hline White & $16(48.5)$ \\
African American & $3(9.1)$ \\
Multiple representation & $11(33.3)$ \\
No representation & $3(9.1)$ \\
Total & $33(100)$ \\
\hline
\end{tabular}

Table 8. Number of prison official(s) depicted.

\begin{tabular}{lc}
\hline & $N(\%)$ \\
\hline 0 & $16(48.5)$ \\
$1-5$ & $16(48.5)$ \\
$6-10$ & $0(0)$ \\
$11-15$ & $1(3.0)$ \\
Total & $33(100)$ \\
\hline
\end{tabular}


Table 9. Type of prison official(s) depicted.

\begin{tabular}{lc}
\hline & $N(\%)$ \\
\hline Correctional officers & $14(42.4)$ \\
Multiple representation & $3(9.1)$ \\
No representation & $16(48.5)$ \\
Total & $33(100)$ \\
\hline
\end{tabular}

official in only one commercial (Table 10). No representation was found in $42.2 \%(n=$ 14) of the sample, as these commercials did not feature prison officials.

\section{Race/ethnicity of prison official(s)}

Prison officials were mostly (17/51.5\%) White (Table 11$)$. Hispanics/Latinos represented $3 \%(n=1)$ of prison officials, and 3\% $(n=1)$ showed multiple race and ethnic representations of prison officials. Of our sample, $42.4 \%(n=14)$ saw no representation, as these commercials did not feature prison officials.

\section{Humor depicted ${ }^{10}$}

Looking at the various forms of humor each commercial may or may not have depicted, we discovered that $40.63 \%(n=13)$ displayed no humor, whereas $31.25 \%(n=10)$ of the commercials relied on dark humor for their message (Table 12). Slapstick humor was found in $15.63 \%(n=5)$ of the commercials, and general humor was only witnessed in $12.5 \%(n=4)$ of the commercials sampled. ${ }^{11}$

Table 10. Gender of prison official(s).

\begin{tabular}{lc}
\hline & $N(\%)$ \\
\hline Male & $18(54.5)$ \\
Female & $1(3.0)$ \\
No representation & $14(42.4)$ \\
Total & $33(100)$ \\
\hline
\end{tabular}

Table 11. Race/ethnicity of prison official(s).

\begin{tabular}{lc}
\hline & $N(\%)$ \\
\hline White & $17(51.5)$ \\
African American & $0(0)$ \\
Hispanic/Latino & $1(3.0)$ \\
Multiple representation & $1(3.0)$ \\
No representation & $14(42.4)$ \\
Total & $33(100)$ \\
\hline
\end{tabular}

Table 12. Rating the humor in each commercial.

\begin{tabular}{lc}
\hline & $N(\%)$ \\
\hline General humor & $4(12.5)$ \\
Slapstick humor & $5(15.63)$ \\
Dark humor & $10(31.25)$ \\
No humor & $13(40.63)$ \\
Total & $32(100)$ \\
\hline
\end{tabular}




\section{Political correctness, or incorrectness}

The political correctness, or incorrectness, of a commercial during the time period in which it aired was measured. Of the sample, $84.38 \%(n=27)$ was considered politically incorrect, whereas $15.63 \%(n=5)$ were viewed as being politically correct (Table 13$)$. The majority of those commercials considered politically correct were PSAs.

\section{Portrayal of prisoner(s)}

With respect to the portrayal of prisoners, $25 \%(n=8)$ of the prisoners featured in the sample were viewed as being the hero (or heroic), whereas $31.25 \%(n=10)$ considered prisoners to be portrayed as the villain (Table 14). Of the commercials in our sample $43.75 \%(n=14)$ did not portray the prisoners in either light.

\section{Portrayal of prison official(s)}

As with prisoners, $62.5 \%(n=20)$, our sample did not portray prison officials as either heroes or villains, whereas $28.13 \%(n=9)$ were viewed as villains (Table 15). Of our sample, $9.38 \%(n=3)$ of the prison officials were observed as being heroes or heroic, and it is important to note that not all of the commercials in our sample featured prison officials, thereby skewing our results for this variable.

\section{Portrayal of being incarcerated}

Incarceration is not a pleasant experience, and this is reflected in our sample. Of our sample $59.38 \%(n=19)$ of the commercials portrayed incarceration as a negative

Table 13. Politically correctness or incorrectness of the commercials.

\begin{tabular}{lr}
\hline & $N(\%)$ \\
\hline Politically correct for the time period & $5(15.63)$ \\
Politically incorrect for the time period & $27(84.38)$ \\
Total & $32(100)$ \\
\hline
\end{tabular}

Table 14. Portrayal of prisoner(s) in the commercial.

\begin{tabular}{lc}
\hline & $N(\%)$ \\
\hline Hero/heroic & $8(25)$ \\
Villain & $10(31.25)$ \\
Neither & $14(43.75)$ \\
Total & $32(100)$ \\
\hline
\end{tabular}

Table 15. Portrayal of prison official(s) in the commercial.

\begin{tabular}{lc}
\hline & $N(\%)$ \\
\hline Hero/heroic & $3(9.38)$ \\
Villain & $9(28.13)$ \\
Neither & $20(62.5)$ \\
Total & $32(100)$ \\
\hline
\end{tabular}


Table 16. Portrayal of being imprisoned.

\begin{tabular}{lc}
\hline & $N(\%)$ \\
\hline Positive experience & $1(3.13)$ \\
Negative experience & $19(59.38)$ \\
Neither/cannot decide & $12(37.5)$ \\
Total & $32(100)$ \\
\hline
\end{tabular}

experience, whereas $3.13 \%(n=1)$ made incarceration appear to be a pleasant experience for everyone (Table 16). Of our sample 37.5\% $(n=12)$ did not portray incarceration in either a positive or negative light, giving the feeling that prison/prisoners were just a backdrop with no real meaning or purpose.

\section{Interpretation}

After consolidating the findings, it appears the average commercial would feature a product and would probably consist of nearly $50 \%$ White convicts and slightly more than $50 \%$ White correctional officers. ${ }^{12}$ This inference gives us pause for concern. Although the numbers are not troubling, why, for example, were the majority of prisoners depicted White? This seems to go against the current demographics of those who are incarcerated in American prisons. In 2014, 37\% of male inmates in the United States state and federal prisons were White, whereas 32\% were African American, and 22\% Hispanics (Carson, 2015, p. 15). Additionally, African American males between ages 18 and 19 were 10 times more likely to be incarcerated in either a state or federal prison than their White counterparts (Carson, 2015, p. 15). Although this rendering does not account for the entire timeline of the commercials released, at the very least more contemporary commercials should in all fairness mirror the racial composition of what inmates look like behind bars. This begs a question. Is the reliance on White convicts based on the fact that advertisers are trying to be politically correct and/or race sensitive? The advertisers may assume that their customer base will most likely be White Americans, and thus they are trying to find prisoners that match them racially. Or this may be a reflection of the composition of the majority of inmates in American correctional facilities in the 1970s or 1980s.

Alternately, White males made up the majority of prison officials depicted in the commercials sampled. Again, we ask if the advertisers were attempting to be politically correct and/or race sensitive? With minorities making up the majority of prisoners in American correctional facilities, one may argue that advertisers are being more race sensitive than politically correct. Had political correctness been an issue, the stereotypical portrayal of prisoners and prison officials seen in the commercials would not exist.

Important, but less significant, is the race of the correctional officers. In the majority of commercials, they were depicted as White. Again, this contrasts with the reality of the current staffing of correctional facilities. According to the most recent statistics provided by the Federal Bureau of Prisons (Federal Bureau of Prisons, 2016), more than $60 \%$ of Whites are staffed within the prison system. ${ }^{13}$ African Americans make up slightly more than $20 \%$ of staff members, whereas other minorities (i.e., Hispanic, Native American, and Asian) have a combined total of a little over $15 \%$ as staff members within the correctional systems (FBOP, 2016). 
Additionally, most of the items advertised were pretty basic (i.e., household cleaners, beverages, and automobiles, etc.). In some cases, the item being advertised was represented by the prisoner himself (i.e., automobile commercials). The PSA commercials provided a more genuine representation of prison life. One could contend that the PSAs, though not promoting household items or automobiles, left viewers with more of a lasting impression.

With the addition of the five new variables, we were able to determine that the majority of the commercials featured in our sample were politically incorrect, with most containing dark humor. However politically incorrect the commercials were, again the majority sampled portrayed being incarcerated as a negative experience. Advertisers, it appears, have been able to find a balance between being offensive to some populations (e.g., individuals who are incarcerated), while remembering that being a prisoner is not an enjoyable experience. Additionally, the majority of the commercials did not portray prisoners and prison officials as heroic or as the villain. It was as if they were just a backdrop, a plot foil, with no real meaning or purpose, as if the advertisers ran out of ideas for characters.

Our sample stretched over a 45-year period, however, the majority of the commercials viewed appeared between 2000 and 2015. The years 2011 to 2014 had the most commercials featuring prisoners, which leads one to ask why this was the case? Is it because society has become so desensitized to our correctional system, or is it something even deeper? Have we as a society started to view prisoners as a population that can be exploited for commercial purposes? This peak period may also be a reflection of access. More recent commercials tend to be archived, because their air time overlapped with the origins of the World Wide Web and the creation of the popular website www.youtube.com.

\section{Conclusion}

The potential to incorporate prisoners, correctional officers, wardens, jails, prisons, and corrections into advertising campaigns and branding is limitless. This process depends in part on the budgets that commercial entities have to spend on the creation, production, and airing of commercials, and the creativity and ability of commercial producers, advertisers, and copywriters to link the symbols and images of corrections with the products and services to be sold.

At their best, the messages conveyed in commercials tend to trivialize the jail and prison experience, including the moral and ethical uses of the death penalty and the seriousness of prison rape. These communications conform to the same old tropes: don't drop the soap, the last dinner request before execution, and the notion and possibilities of escape. In some instances, these commercials make a prison sentence seem more acceptable and fun, though at other times incarceration appears more dangerous than it really is.

In short, commercials depicting prisoners, correctional officials, and carceral themes provide the public with a moderated and less-than-satisfactory peek inside a complex, foreign, and often foreboding structure. It allows us to look at, but not really engage with, the subject matter, thus reinforcing our previous beliefs (Brown, 2009). Perhaps nothing more is to be expected when such a complex environment is communicated to the public in the furtherance of consumption. We would hope, however that in the future that the consumer and producer of television commercials would also acknowledge their moral 
and ethical responsibility to question the role and practice of corrections so that they would better accomplish their goals. Although there may be community standards, there may not really be policy implications. Why? The production of commercials runs into issues of free speech. As long as advertisers do not impinge upon community standards of good taste then they are relatively free to depict situations as they wish.

Future research on this topic could involve interviews with the advertisers who produced these commercials to better determine their reasons for the way they chose to portray the carceral themes embedded in their advertisements. Alternative scholarship might involve showing these commercials to a select sample of viewers to gauge their reactions. These approaches would allow us to tease out additional nuances that a content analysis like the one conducted here cannot properly achieve.

\section{Notes}

1. The words convict, inmate, and prisoner are used interchangeably throughout this article.

2. As the scholarly study of corrections should demonstrate, the field of jails, prisons, correctional officers, and inmates is more complicated than the public assumes it to be.

3. Numerous arguments can be made for focusing on American commercials, including the high jail and prison population in the United States and the ease of archival access to this material (Anonymous, n.d., 2010, 2016).

4. Horton is the prisoner who, after being released from prison in Massachusetts-Dukakis' home state-raped and killed Angela Miller (Hacker \& Swan, 1992; Jamieson, 1989; Mendelberg, 1988).

5. It was not possible to identify the year for one of the commercials, and therefore marked as missing.

6. The coding sheet was developed using the following variables: length of commercial by seconds, advertising type, message packaged around advertisement, number of prisoner(s), gender of prisoner(s), race/ethnicity of prisoner(s), number of prison official(s), type of prison official(s) depicted, gender of prison official(s), and race/ethnicity of prison official(s). A document was then created, separate from the coding sheet, that included the commercial name, identifier, and URL to assist with future coding.

7. For example, the researchers ran into a couple of cases where after locating a URL during the earlier part of data collection, the video could no longer be found when a follow-up was done.

8. Research Assistant 1 was given a document with the relevant URLs and a coding sheet. Over a 4-hour period, the assistant completed the coding of the commercials, and it was discovered at this time that one of the sample commercials was no longer attached to the URL provided. The coauthor did an extensive search of the Internet for the commercial, but it could not be located, thus reducing our final sample to 32 commercials.

Research Assistant 2 spent approximately 5 hours coding the new sample of 32 commercials. Next, the coauthor compared the three coding sheets, discovering that each commercial viewed by the three had a minimum of two discrepancies in the coding of the variables-the majority of these were found in the message packaged around the advertising and the race/ ethnicity of the prisoner(s). The coauthor proceeded to rewatch the commercials, recoding and correcting any discrepancies. From there, the coauthor entered the new data into the SPSS database and ran a frequencies query with the updated sample set.

9. Again, the co-author viewed each commercial first for coding purposes, followed by the work of two research assistants. And as with the original coding, the coauthors followed the same guidelines as before in which they rewatched each commercial, recoding, and correcting any discrepancies. The data was entered into the original SPSS database (now with the addition of the five new variables), and a new frequency query was run. 
10. Because the next five variables were coded at a later time, only 32 out of the previously coded 33 commercials were accessible via the World Wide Web.

11. We defined slapstick humor as "deliberately clumsy actions and humorously embarrassing events," and dark humor as humor that "makes light of themes that are generally considered serious of taboo." Definitions were derived from www.dictionary.com.

12. Ranges instead of actual numbers were coded for number of prisoners and correctional officials.

13. The authors understand that the Federal Bureau of Prisons is only a fraction of all prison systems in the United States.

\section{Acknowledgements}

Special thanks to Joffrey Alcidor for identifying some of the videos, Tara Moon and Sonce Reece for assistance with coding, and the comments of the anonymous reviewers of this journal.

\section{References}

Allan, K., \& Coltrane, S. (1996). Gender displaying television commercials: A comparative study of television commercials in the 1950s and 1980s. Sex Roles, 35(3/4), 185-201.

Althusser, L. (1971). Ideology and ideological state apparatuses. In L. Althuser (Ed.), Lenin and philosophy and other essays (pp. 121-176). (Translated by B. Brewster). New York, NY: Monthly Review Press.

Anderson, D. (1995). Crime and the politics of hysteria: How the Willie Horton story changed American justice. New York, NY: Times Books.

Anonymous. (n.d.) Statistics and facts about the advertising industry in the United States. Statista. Retrieved from April 21, 2017 from http://www.statista.com/topics/1979/advertising-in-the-us/.

Anonymous (2010). Research study shows TV viewers really do watch commercials. Retrieved April 21, 2017 from www.nielson.com/US/en/insights/news/2010/research-study-shows-tv-viewersreally-do-watch-commercials.html.

Anonymous (2016). Big data + analytics: Television watching statistics. Statistics Brain. Retrieved April 21, 2017 from www.statisticsbrain.com/television-watching-statistics.

Ball, J. G., Liang, A., \& Lee, W. N. (2009). Representation of African Americans in direct-toconsumer pharmaceutical commercials: A content analysis with implications for health disparities. Health Marketing Quarterly, 26(4), 372-390.

Barak, G. (Ed.). (1991). Crimes by the capitalist state: An introduction to state criminality. Albany, NY: State University of New York Press.

Bardwick, J., \& Schumann, S. (1967). Portrait of American men and women in TV commercials. Psychology, 4(4), 18-23.

Baumann, S., \& Ho, L. (2014). Cultural schemas for racial identity in Canadian television advertising. Canadian Review of Sociology/Revue Canadienne de Sociologie, 51(2), 152-169.

Beckett, K., \& Murakawa, N. (2012). Mapping the shadow carceral state: Toward an institutionally capacious approach to punishment, Theoretical Criminology. 16(2), 221-244.

Bretl, D. J., \& Cantor, J. (1988). The portrayal of men and women in U.S. television commercials: A recent content analysis and trend over 15 years. Sex Roles, 18(9/10), 595-609.

Brown, M. (2009). The culture of punishment: Prison, society, and spectacle. New York, NY: New York University Press.

Bureau of Labor Statistics. (2015). American time use survey summary (USDL-15-1236). Retrieved from http://www.bls.gov/news.release/atus.nr0.htm.

Carson, E. A. (2015). Prisoners in 2014 (NCJ 248955) Retrieved from http://www.bjs.gov/content/ pub/pdf/p14.pdf.

Comstock, G. (1991). Television in America. Newbury Park, CA: Sage. 
Courtney, A. E., \& Whipple, T. W. (1985). Female role portrayals in advertising and communication effectiveness: A review. Journal of Advertising, 14, 4-8, 16-17.

Cullen, F. T. \& Gendreau, P. (1989). The effectiveness of correctional rehabilitation: reconsidering the 'nothing works' debate. In L. Goodstein \& MacKenzie (Eds.), American prisons: Issues in research and policy (pp. 23-44). New York, NY: Plenum.

Dominick, J. R., \& Rauch, G. E. (1972). The image of women in network TV commercials. Journal of Broadcasting, 16(1), 259-265.

Elliott, S. (1995, May 9). Advertising. New York Times, p. D7.

Federal Bureau of Prisons. (2016, April 23) BOP statistics: Staff ethnicity/race. Retrieved from https://www.bop.gov/about/statistics/statistics_staff_ethnicity_race.jsp.

Ferrante, C. L., Haynes, A. M., \& Kingsley, S. M. (1988). Image of women in television advertising. Journal of Broadcasting and Electronic Media, 3(2), 231-237.

Ferrell, J., Hayward, K., \& Young, J. (2008). Cultural criminology. London, UK: Sage.

Garland, D. (2001). The culture of control: Crime and social order in contemporary society. Chicago, IL: University of Chicago Press.

Gerbner, G. (1998). Cultivation analysis: An overview. Mass Communication and Society, 1(3/4), 175-194.

Geis, F. L., Brown, V., Jennings, J., \& Porter, N. (1984). TV commercials as achievement scripts for women. Sex Roles, 10(7/8), 513-525.

Gilly, M. C. (1988). Sex roles in advertising: A comparison of television advertisements in Australia, Mexico and the United States. Journal of Marketing, 52(2), 75-86.

Gottschalk, M. (2010). Cell blocks \& red ink: Mass incarceration, the great recession \& penal reform. Daedalus, 139(1), 62-73.

Gottschalk, M. (2011). The past, present, and future of mass incarceration in the United States. Criminology \& Public Policy, 10(3), 483-504.

Gottschalk, M. (2014). Caught: The prison state and the lockdown of American politics. Princeton, NJ: Princeton University Press.

Graig, R. S. (1992). Women as home caregivers: Gender portrayal in OTC drug commercials. Journal of Drug Education, 22(4), 303-312.

Gramsci, A. (2012). Selections from the prison notebooks. (Q. Hoare \& G. Nowell Smith, Eds. and Trans.). New York, NY: International Publishers (Original work published 1971).

Hacker, K. L., \& Swan, W. O. (1992). Content analysis of the Bush and Dukakis 1988 presidential election campaign television commercials. Journal of Social Behavior \& Personality, 7(3), 367-374.

Hall, C. I., \& Crum, M. J. (1994). Women and bodyisms in television beer commercials. Sex Roles, $31(5 / 6), 329-337$.

Hayward, K. (2009). Visual criminology: Cultural criminology-style, Criminal Justice Matters, 78(1), $12-14$.

Hayward, K., \& Presdee, M. (2010). Framing crime: Cultural criminology and the image. London, UK: Routledge.

Hetsroni, A. (2010). Violence in mainstream TV advertising: A comparison of the representation of physical aggression in American and Israeli commercials. Communications, 35(1), 29-44.

Hetsroni, A. (2011). Violence in television advertising: Content analysis and audience attitudes. Atlantic Journal of Communication, 19(2), 97-112.

Holsti, O. R. (1969). Content analysis for the social sciences and humanities. Reading, MA: Addison Wesley.

Jamieson, K. H. (1989). Context and the creation of meaning in the advertising of the 1988 presidential campaign. American Behavioral Scientist, 32(4), 415-424.

Kellner, D. (1990). Television and the crisis of democracy. Boulder, CO: Westview Press.

Knill, B. J., Pesch, M., Pursey, G., Gilpin, P., \& Perloff, R. M. (1981). Still typecast after all these years? Sex role portrayals in television advertising. International Journal of Women's Studies, 4(5), 497-506.

Krippendorf, K. (1981). Content analysis: An introduction to its methodology. Beverly Hills, CA: Sage. 
Maguire, B., Sandage, D., \& Weatherby, G. A. (2000). Violence, morality, and television commercials. Sociological Spectrum, 20(1), 121-143.

Mastro, D. E., \& Stern, S. R. (2003). Representations of race in television commercials: A content analysis of prime-time advertising. Journal of Broadcasting \& Electronic Media, 47(4), 638-647.

Mendelberg, T. (1988). Executing Hortons: Racial crime in the 1988 presidential campaign. Public Opinion Quarterly, 61(1), 134-157.

Murakawa, N. (2014). The first civil right: How liberals built prison America. New York, NY: Oxford University Press.

Perreault, W.D., \& Leigh, L.E. (1989). Reliability of nominal data based on qualitative judgments. Journal of Marketing, 26, 135-148.

Pratt, J., Brown, D., Brown, M., Hallsworth, S., \& Morrison, W. (Eds.). (2013). The new punitiveness. London, UK: Routledge.

Riff, D., Lacy, S., \& Fico, F. (2014). Analyzing media messages: Using quantitative content analysis in research. New York, NY: Routledge.

Rosenberger, J., \& Callanan, V. (2011). The influence of media on penal attitudes. Criminal Justice Review, 36(4), 435-455.

Ross, J. I. (Ed.). (2000). Controlling state crime: An introduction. New Brunswick, NJ: Transaction Publishers. (Original work published 1995)

Ross, J. I. (2000a). Making news of police violence: Comparing Toronto and New York City. Westport, CT: Praeger.

Ross, J. I. (Ed.). (2000b). Varieties of state crime and its control. Monsey, NJ: Criminal Justice Press.

Ross, J. I. (2003). (Mis)representing corrections: The role of our cultural industries. In J. I. Ross \& S. C. Richards (Eds.), Convict criminology (pp. 37-58). Belmont, CA: Wadsworth Publishing.

Ross, J. I. (2012). Debunking the myths of American corrections. Critical Criminology: An International Journal, 20(4), 409-421.

Rothe, D. L. (2009). State criminality: The crime of all crimes. Latham, MD: Lexington/Roman and Littlefield.

Scharrer, E., Bergstrom, A., Paradise, A., \& Ren, Q. (2006). Laughing to keep from crying: Humor and aggression in television commercial content. Journal of Broadcasting \& Electronic Media, 50(4), 615-634.

Schiller, H. (1989). Culture Inc., the corporate takeover of public expression. New York, NY: Oxford University Press.

Signorielli, N. (1991). A sourcebook on children and television. New York, NY: Greenwood Press.

Signorielli, N., \& Lears, M. (1992). Children, television, and conceptions about chores: attitudes and behaviors. Sex Roles, 27(1), 157-170.

Simon, J. (2000). The "society of captives" in the era of hyper-incarceration. Theoretical Criminology, 4(1), 285-308.

Simon, J. (2010). Do these prisons make me look fat? Moderating the USA's consumption of punishment. Theoretical Criminology, 14(3), 257-272.

Tamburro, R. F., Gordon, P. L., D’Apolito, J. P., \& Howard, S. C. (2004). Unsafe and violent behavior in commercials aired during televised major sporting events. Pediatrics, 114(60), 694698.

Tribune News Service. (1998, March 18). Spending on commercials exceeds $\$ 32$ billion. Chicago Tribune, Section 12, p. 6.

Wacquant, L. (2001). Deadly symbiosis when ghetto and prison meet and mesh. Punishment \& Society, 3(1), 95-133.

Walstad, D. (1997, October 6). The incredible shrinking 1-hour show. Chicago Tribune, Section 2, p. 4.

Weaver, V. M., \& Lerman, A. E. (2010). Political consequences of the carceral state. American Political Science Review, 104(4), 817-833.

Williamson, J. (1994) Decoding advertisements. New York, NY: Marion Boyars Publishers Ltd..

Wilson, J. Z. (2008). Prison: Cultural memory and dark tourism. New York, NY: Peter Lang.

Wright, P. L. (2000). The cultural commodification of prisons. Social Justice. 27(3), 15-21. 